\title{
Avaliação tomográfica e histológica da técnica de levantamento de seio maxilar e instalação de implantes dentários sem utilização de biomaterial com acompanhamento de 36 meses : Relato de caso
}

Tomographic and histological study of maxillary sinus lift technique and dental implants placement without use of biomaterial with a 36-month followup: Case Report

Estudio tomográfico e histológico de la técnica de elevacíon des seno maxilar y Colocación de implantes dentales sin uso de biomaterial con seguimiento de 36 meses: Reporte de caso

Pedro Henrique Silva Gomes Ferreira

ORCID: https://orcid.org/0000-0002-8936-3662 Universidade Estadual Paulista, Brasil E-mail: pedroferreirabmf@gmail.com

Vinícius Ferreira Bizelli

ORCID: https://orcid.org/0000-0003-1813-3509 Universidade Estadual Paulista, Brasil E-mail: v.bizelli@unesp.br

Dercelino Bittencourt Junior

ORCID: https://orcid.org/0000-0001-9925-1819 Instituto Latino Americano de Pesquisa e Ensino Odontológico, Brasil E-mail: dercelinojunior@hotmail.com

Flávia Gasparini Kiatake Fontão

ORCID: https://orcid.org/0000-0002-3924-7743 Instituto Latino Americano de Pesquisa e Ensino Odontológico, Brasil E-mail: fgaspar@ilapeo.com.br

Ana Paula Farnezi Bassi

ORCID: https://orcid.org/0000-0002-0031-4953 Universidade Estadual Paulista, Brasil E-mail: ana.bassi@unesp.br

\begin{abstract}
Resumo
Este trabalho teve como objetivo avaliar quantitativo e qualitativamente a formação óssea periimplantar na cirurgia de elevação do seio maxilar sem utilização de biomaterial por meio de análise tomográfica e histológica. Paciente atendido no Instituto Latino Americano de Ensino e Pesquisa Odontológica (ILAPEO) para reabilitação da região posterior de maxila bilateral com escasso volume ósseo, foi realizado então levantamento de seio e instalação de implantes sem utilização de biomaterial. O acompanhamento pós operatório foi conduzido através de condições clínicas e tomográficas, no pós-operatório imediato, 3, 6, 9 e 36 meses. Aos 9 meses pós operatório, com o auxilio de uma trefina de $2 \mathrm{~mm}$ foi removido uma biópsia local para realização de uma análise histológica. Pode-se observar tomográficamente, que a maior densidade encontrada nos períodos avaliados, foi aos 36 meses (vestibular 1766,5 e palatina 1716,75), ou seja, após aplicação de carga funcional. A análise histológica mostrou que aos 9 meses a biópsia removida pela trefina era compostos de $52 \%$ de tecido ósseo e $48 \%$ de tecido conjuntivo, apresentando uma citoarquitetura óssea compatível de fato com osso maduro com poucas áreas de osso imaturo. Em conclusão, a técnica de elevação do seio maxilar com colocação imediata do implante, sem o uso de biomateriais quando bem indicada, pode ser realizada com sucesso obtendo ganho de volume ósseo periimplantar com qualidade.
\end{abstract}

Palavras-chave: Neoformação óssea; Coágulo sanguíneo; Implante imediato; Densidade óssea.

\begin{abstract}
The aim of this study was to quantitatively and qualitatively evaluate peri-implant bone formation in maxillary sinus lift surgery without using biomaterial by means of tomographic and histological analysis. Patient attended the Latin American Institute of Dental Education and Research (ILAPEO) for rehabilitation of the posterior region of bilateral maxilla with low bone volume, sinus lift, and implant placements without biomaterial were performed. The postoperative follow-up was conducted through clinical and tomographic conditions, in the immediate postoperative, $3,6,9$, and 36 months. During the postoperative period of 9 months, a local biopsy was performed with the aid of a 2 $\mathrm{mm}$ trephine to perform a histological analysis. It can be observed tomographically that the highest density found in
\end{abstract}


the evaluated periods was 36 months (buccal 1766,5 and palatal 1716,75), that is, after application of functional load. Histological analysis showed that at 9 months the biopsy removed by trephine was composed of $52 \%$ of bone tissue and $48 \%$ of connective tissue, presenting a bone cytoarchitecture compatible with mature bone with few areas of immature bone. In conclusion, this technique, can be performed successfully, obtaining a gain of peri-implant bone volume with quality.

Keywords: Bone neoformation; Blood clot; Immediate implants; Bone density.

\section{Resumen}

El objetivo de este estudio fue evaluar cuantitativa y cualitativamente el periimplante formación ósea en cirugía de elevación de seno maxilar sin utilizar biomaterial mediante análisis tomográfico e histológico. El paciente acudió al Instituto Latinoamericano de Educación e Investigación Odontológica (ILAPEO) para rehabilitación de la región posterior de maxilar bilateral con bajo volumen óseo, elevación de seno y colocación de implantes sin biomaterial. El seguimiento postoperatorio se realizó mediante condiciones clínicas y tomográficas, en el postoperatorio inmediato, a los 3, 6, 9 y 36 meses. Durante el postoperatorio de 9 meses se realizó una biopsia local con la ayuda de un trépano de $2 \mathrm{~mm}$ para realizar un análisis histológico. Se puede observar tomográficamente que la mayor densidad encontrada en los períodos evaluados fue de 36 meses (bucal 1766,5 y palatino 1716,75), es decir, después de la aplicación de carga funcional. El análisis histológico mostró que a los 9 meses la biopsia extraída por trépano estaba compuesta por un $52 \%$ de tejido óseo y un $48 \%$ de tejido conjuntivo, presentando una citoarquitectura ósea compatible con hueso maduro con pocas áreas de hueso inmaduro. En conclusión, esta técnica, se puede realizar con éxito, obteniendo una ganancia de volumen óseo periimplantario con calidad.

Palabras clave: Neoformación óssea; Coágulo sanguíneo; Implantes inmediatos; Densidad ósea.

\section{Introduçãa}

Rotineiramente o levantamento de seio é realizado nos consultórios odontológicos, de maneira que forneça altura óssea necessária para instalação de implantes na região posterior da maxila (Thor et al., 2007; Stern et al., 2012). Esta técnica, pode ser realizada isolada ou associada a instalação de implante imediata, com resultados satisfatórios e formação óssea significante na região (Thor et al., 2007; Lin et al., 2010). Para o procedimento, biomateriais são as principais fontes utilizadas como interposição entre a membrana do seio maxilar e remanescente ósseo do rebordo alveolar (Pinchasov et al., 2010), porem estudos recentes vem mostrando uma vertente em potencial para formação óssea nessas regiões sem utilização de biomateriais, a qual vem mudando as perspectivas dos cirurgiões a respeito deste assunto (Moon et al., 2011; Sohn et al., 2008; Bassi et al., 2015; Falah et al., 2016).

Neste contexto, está técnica deve ser realizada em conjunto a instalação de implantes, em que a altura óssea mínima de $5 \mathrm{~mm}$ de rebordo alveolar é necessária (Bassi et al., 2015), com este procedimento a manutenção da membrana do seio pode ser realizada usando apenas coágulo de sangue local (Thor et al., 2007; Lin et al., 2010; Bassi et al., 2015; Falah et al., 2016). No momento há uma tendência crescente na realização deste procedimento com bons resultados de formação óssea e ganho de volume (Bassi et al., 2015; Falah et al., 2016; Lundgren et al., 2008).

Para avaliação destes ganhos, a tomografia computadorizada é indispensável, a qual deve ser realizado tomadas pre e pós-operatória, para avaliação longitudinal dos parâmetros de ganho e manutenção de volume ósseo no interior do seio maxilar ao redor do implante (Thor et al., 2007; Stern et al., 2012; Lin et al., 2010; Bassi et al., 2015; Lundgren et al., 2008). Com esta análise a observação da formação óssea é possível, porém é de fundamental importância, que os padrões de qualidade óssea também sejam analisados. Para tanto, a analise histológica deve ser realizada visando a avaliação da citoarquitetura óssea formada nesta região (Moon et al., 2011; Falah et al., 2016), apresentando assim um padrão quantitativo pela análise tomográfica e qualitativo pela avaliação histológica.

Sendo assim, este trabalho teve como objetivo avaliar quantitativo e qualitativamente a formação óssea periimplantar na cirurgia de elevação do seio maxilar sem utilização de biomaterial por meio de análise tomográfica e histológica. 


\section{Metodologia - Caso clínico}

\subsection{Análise Tomográfica}

Com o auxilio do software Galaxis versão 1.7 (Sirona, Bensheim, Germany) as imagens tomográficas foram analisadas. O parâmetro de pós-processamento apresentados foi em espessura de corte e distância de 0,3 milímetros.

A avaliação do osso neoformado foi realizada de maneira quantitativa (Pereira, et al., 2018), bilateralmente através da mensuração da densidade óssea pela diferença dos tons de cinza pelo software. As densidades mensuradas foram obtidas em áreas padronizadas entre as linhas de referencias dos 4 implantes ( 2 seio maxilar direito e 2 seio maxilar esquerdo) usando a função "visualização do valor de cinza". Foi obtido três medições na região palatina de cervical para apical (P1, P2 e P3) e 3 medições na região vestibular (B1, B2 e B3). Os valores foram transferidos para o software Microsoft Office Excel 2003 (Microsoft Corporation, EUA) e então realizado as médias para avaliação (Figura 1).

Figura 1 - Corte coronal representativo demonstrando as áreas analisadas na região palatina (P1, P2 e P3) e vestibular (B1, B2 e B3) pela diferença dos tons de cinza.

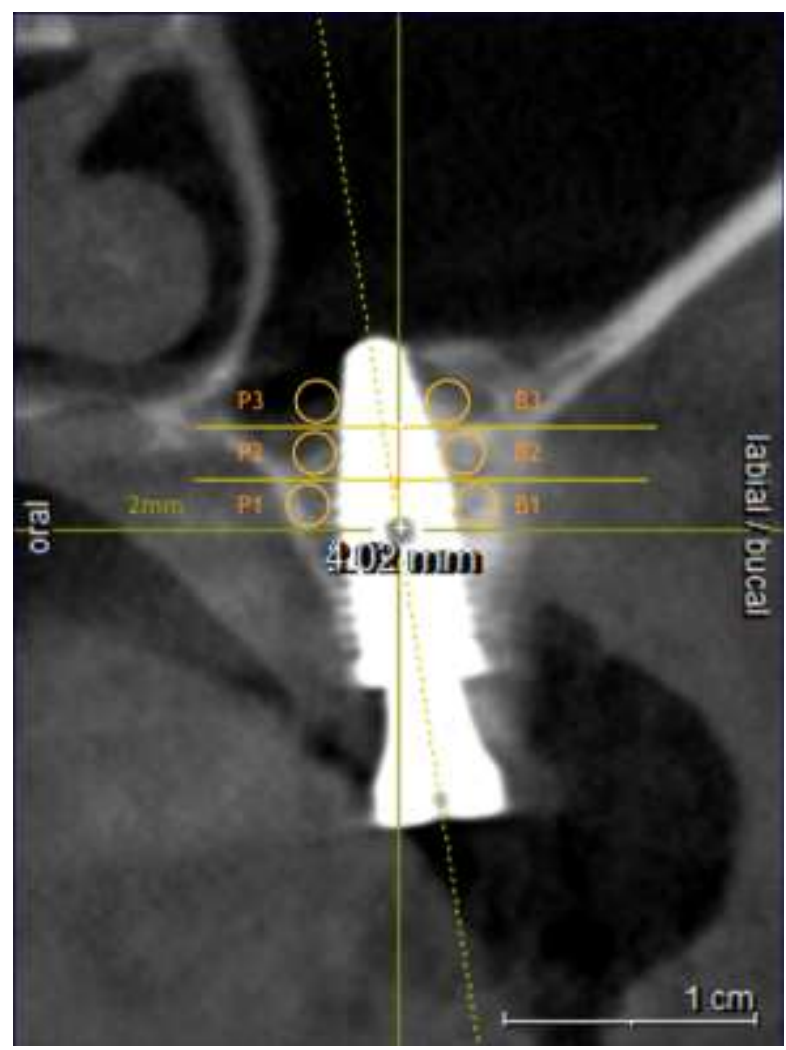

Fonte: Exame de Tomografia Computadorizada de Feixe Cônico - Software Galaxis versão 1.7 (Sirona, Bensheim, Germany)

\subsection{Análise Histomorfométrica}

A biópsia óssea removida do seio maxilar foi fixada em solução de formaldeido $10 \%$ durante 48 horas, lavada em água corrente por 24 horas, descalcificada em EDTA 20\% por seis semanas, desidratada em sequência de álcoois e diafanizada em xilol. A peça obtida foi incluída em parafina e cortadas em micrótomo, obtendo cortes de $6 \mu \mathrm{m}$ de espessura e posteriormente, montadas em lâminas.

As laminas obtidas foram coradas com hematoxilina e eosina (HE) para a análise histomorfométrica da neoformação do tecido ósseo no seio maxilar. A lâmina foi examinada através de um microscópio de luz com objetiva de 12,5X. As imagens foram obtidas com uma câmera digital (JVC TK1270 Color Video Câmera) acoplada ao microscópio e analisadas por meio da 
grade de Merz (Figura 2). A imagem, com a grade anexada, foi montada no programa Keynote versão 7.0 (3507 - Apple Inc., EUA) onde se contou os pontos referentes a serem analisados para, enfim, obter o percentual de osso formado e de tecido conjuntivo da amostra. Foi também observado o osso formado em aumento de 40X, para avaliação qualitativa (Pereira A.S. et al., 2018) referente a citoarquitetura óssea.

Figura 2 - Grade de Merz para análise histológica qualitativa da biópsia removida com auxílio da trefina de $2 \mathrm{~mm}$ de diâmetro, magnificação de 12,5x.

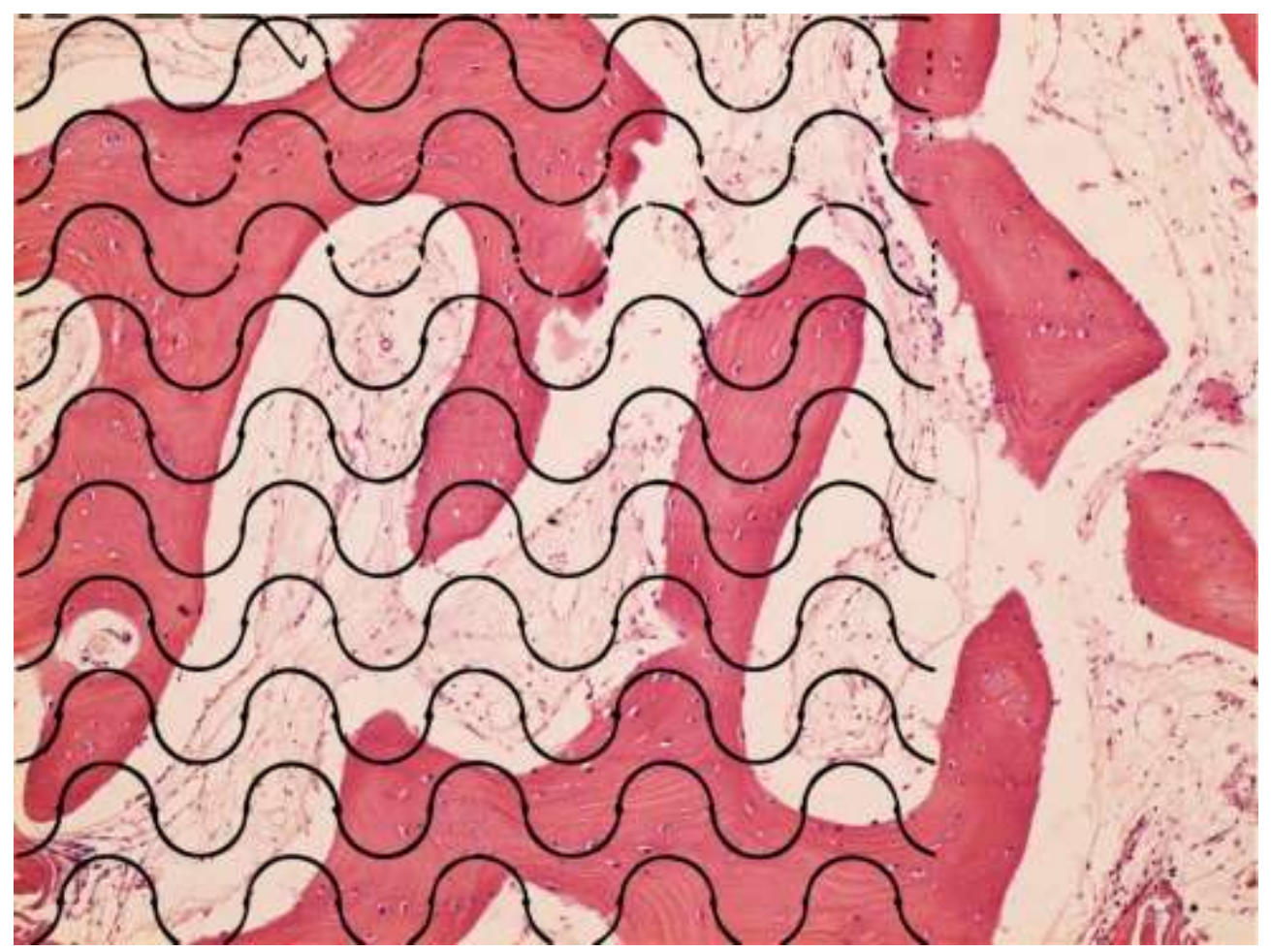

Fonte: Secão histológica da biópsia - Software ImageJ.

\subsection{Relato de Caso}

Paciente atendido no Instituto Latino Americano de Ensino e Pesquisa Odontológica (ILAPEO) para reabilitação da região posterior de maxila bilateral. Para diagnóstico, uma tomografia computadorizada foi solicitada. Através desta, foi possível avaliar o remanescente ósseo, o qual se apresentava escasso na região posterior da maxila direita e esquerda com 5 $\mathrm{mm}$ e $6 \mathrm{~mm}$ respectivamente, indicando assim a necessidade de ganho ósseo em altura nessa região de seio maxilar para a inserção de implantes (Figura 3). Após revisão da literatura vigente, o tratamento eleito para a paciente foi elevação da membrana do seio maxilar sem utilização de biomaterial e instalação imediata de dois implantes em cada lado. 
Figura 3 - Reconstrução panorâmica do exame tomográfico da maxila mostrando o remanescente ósseo.

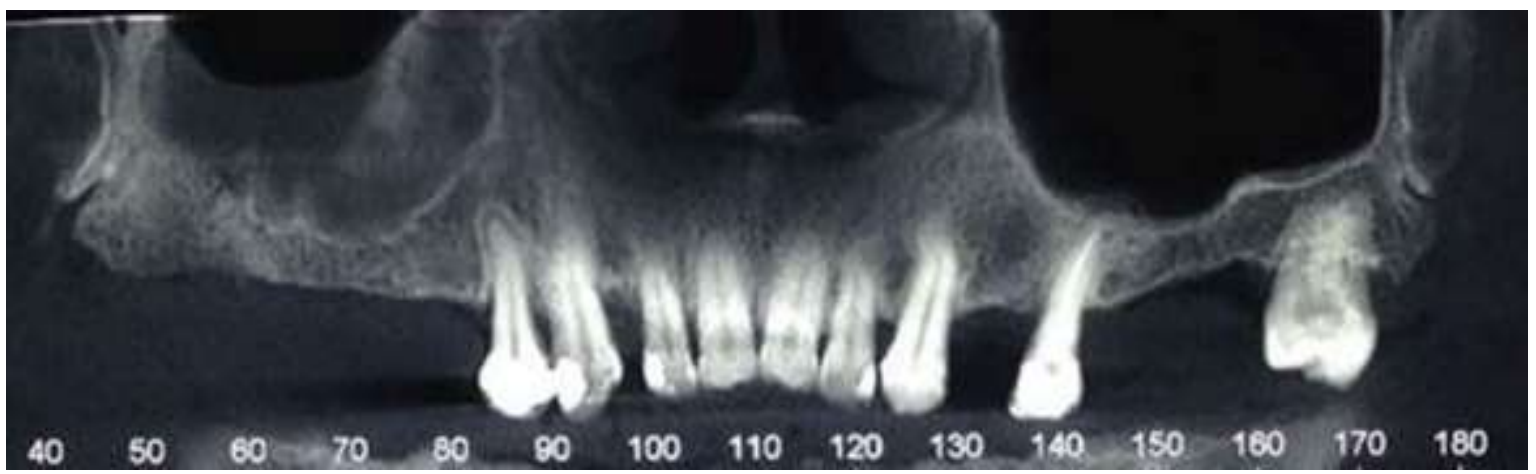

Fonte: Exame de Tomografia Computadorizada de Feixe Cônico.

Sendo assim, sob anestesia local (mepivacaína com epinefrina1:100.000 - Mepíadre, DFL Indústria e Comércio S.A., Rio de Janeiro, RJ, Brasil) em âmbito ambulatorial, uma incisão bilateral na crista alveolar foi realizada associada a uma incisão obliqua anterior. Após descolamento mucoperiosteal e exposição da crista óssea e parede anterior do seio maxilar, uma osteotomia com broca esférica diamantada foi realizada na parede do seio. A elevação da membrana sinusial realizada com auxilio de cureta para levantamento de seio, esta etapa foi realizada de forma que mantivesse uma porção óssea aderida a membrana. Tendo em vista a técnica descrita (Bassi et al., 2015), esta parede óssea foi mantida como anteparo, a qual devera estar em intimo contato com o ápice do implante instalado, formando por sua vez um teto e mantendo a membrana elevada em posição. A instalação dos implantes Neodent (Curitiba, Paraná, Brasil) cone-morse Alvim de $4.1 \times 13$ mm, com tratamento de superfícies, foi realizada pelo sistema de fresagem bilateralmente, sendo então utilizado dois destes de cada lado (Figura 4A e B).

Figura 4 - Instalação de dois implantes no lado direto (A) e lado esquerdo (B), fazendo com que o ápice do implante segura a parede óssea vestibular deslocada para dentro da cavidade sinusal, permitindo a manutenção do coágulo.

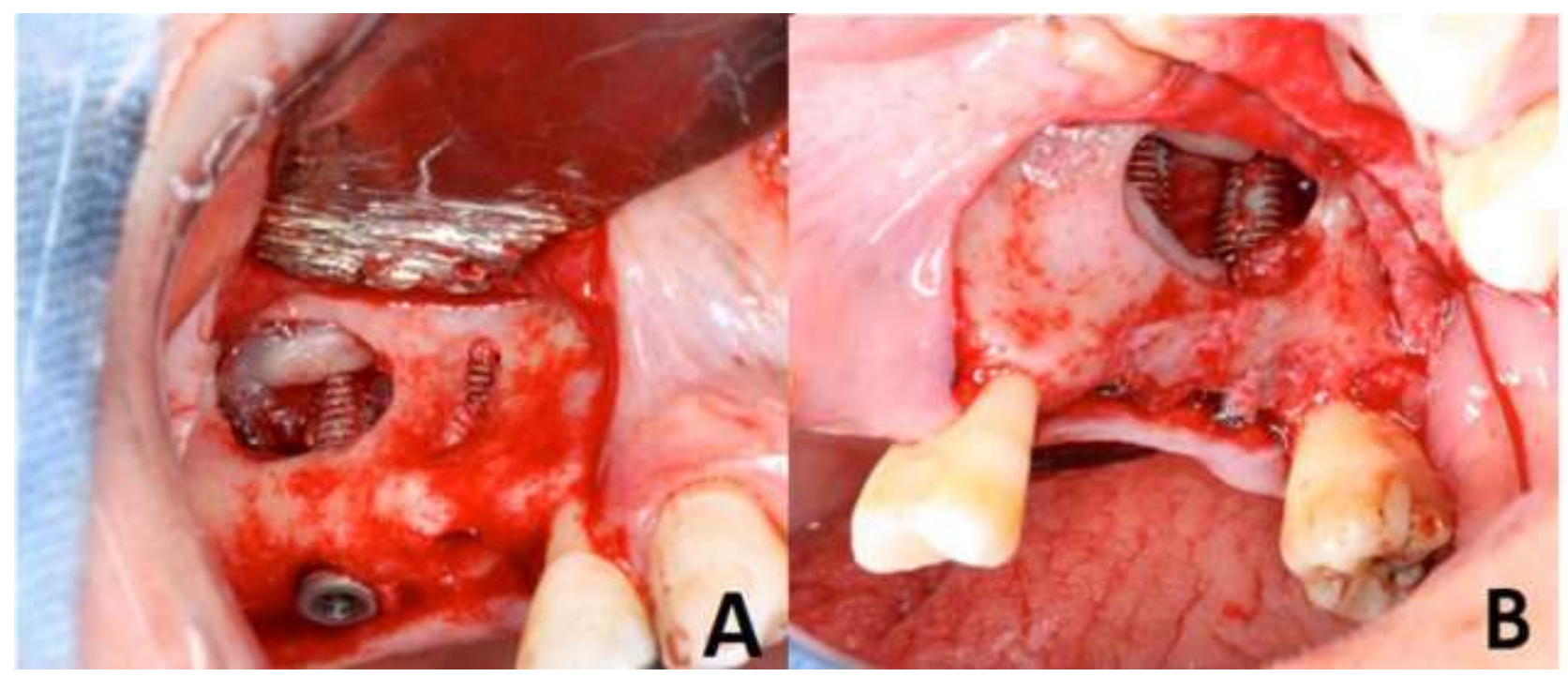

Fonte: Autores. 
O defeito ósseo no seio maxilar foi preenchido apenas com coagulo do sangramento local, não sendo utilizado nenhum tipo de biomaterial. Para fechamento da parede anterior do defeito, uma membrana não absorvivel Alúmina (Maxtron, Belo Horizonte, Minas Gerais, Brasil) com espessura de 0,06mm foi utilizada, a qual foi fixada com auxilio de um parafuso de enxerto (Figura $5 \mathrm{~A}$ e B).

Figura 5 - Membrana não absorvível Alúmina (Maxtron, Belo Horizonte, Minas Gerais, Brasil) fixada no lado direito (A) e esquerdo (B) para isolar a janela óssea.

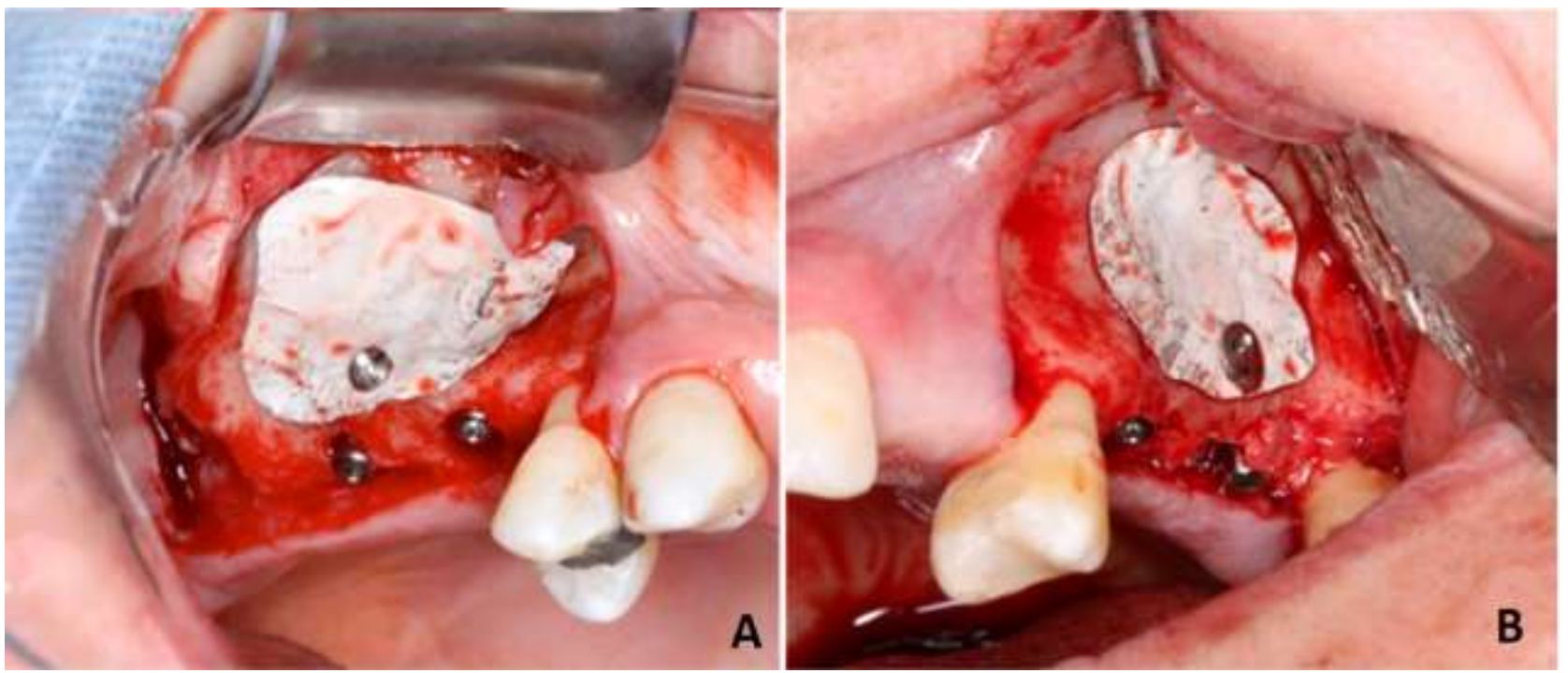

Fonte: Autores.

O acompanhamento pós operatório foi conduzido através de condições clínicas e topográficas, no pós-operatório imediato, 3, 6, 9 e 36 meses. As imagens topográficas foram obtidas com um equipamento de tomografia computadorizada do tipo cone-beam e avaliadas pelo software Galileos. O equipamento foi operado de $14 \mathrm{mAs}$ a $85 \mathrm{mAs}$ com $85 \mathrm{Kv}$.

Durante a reabertura dos implantes aos 9 meses pós-operatório, as membranas não reabsorveis foram removidas e os cicatrizadores instalados. Com o auxilio de uma trefina de $2 \mathrm{~mm}$ foi removido o osso formado no seio maxilar entre os dois implantes instalados do lado direito na região apical, em que a trefina foi posicionada no sentido vestíbulo-palatino e de superior para inferior, em região apical . Esta amostra foi submetida a analise histológica após ser processada e corada em hematoxilina e eosina (HE), para avaliação hitométrica e da citoarquitetura óssea formada na região da elevação da membrana sinusial sem uso de biomaterial (Figura 6A, B e C). 
Figura 6 - (A) Trefina de $2 \mathrm{~mm}$ de diâmetro posicionada no sentido vestíbulo-lingual para remoção da biópsia. (B) Biópsia removida no interior da broca trefina. (C) região de coleta da biópsia, demosntrando não atingir a direção dos implantes.

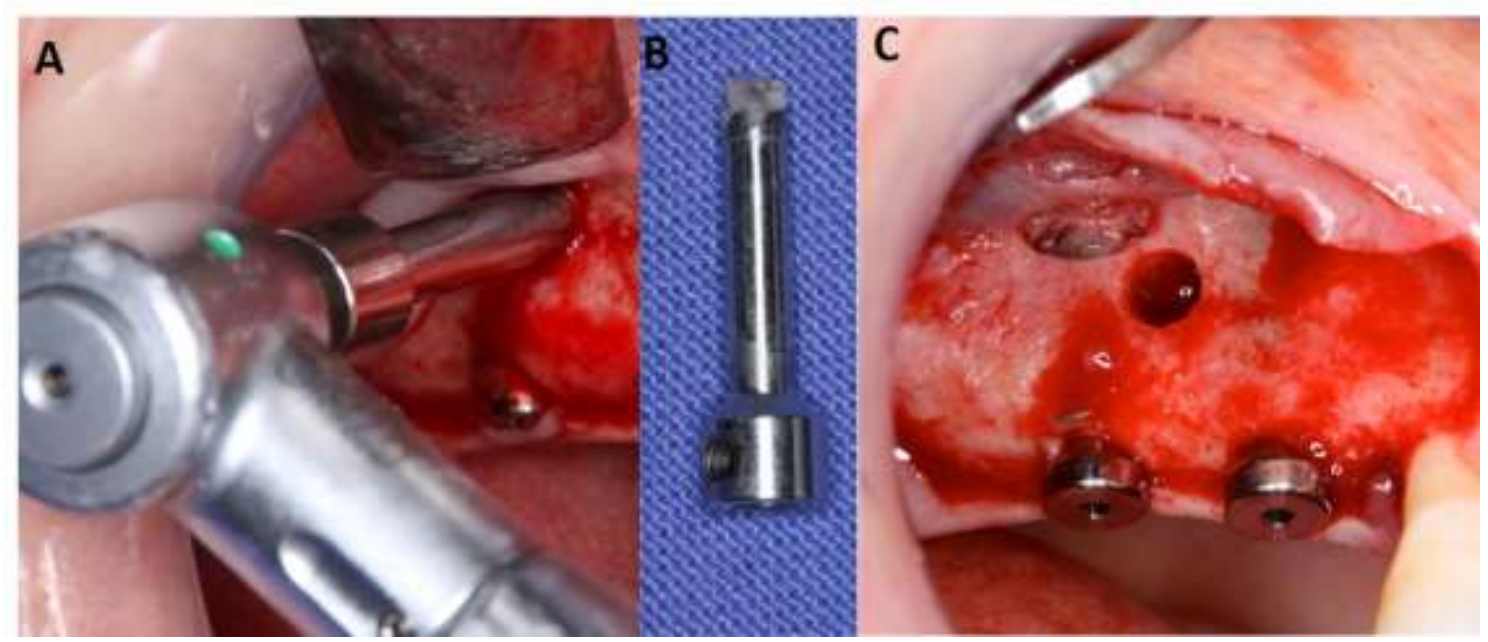

Fonte: Autores.

Após a cicatrização gengival, os passos de moldagem e prova das estruturas protéticas foram realizados, até a instalação das próteses e uma ultima analise tomográfica foi feita aos 36 meses após carga funcional para avaliar a densidade óssea periimplantar a longo prazo.

\section{Resultados}

\subsection{Análise Tomográfica}

Ao avaliarmos a densidade óssea pela diferença dos tons de cinza, nos diferentes tempos avaliados pela TC (Pós operatório imediato, 3, 6 e 36 meses), a densidade óssea vestibular (DV) apresentou valores médios aproximados no período pós operatório imediato $(1342,75)$ e 3 meses (1303), com aumento da densidade óssea aos 6 meses pós operatório $(1366,25)$, após a instalação da prótese e aplicação de carga funcional nestes implantes, no pós operatório de 36 meses pode observar a maior densidade óssea para esta região com valor 1766,5. Já a densidade óssea palatina (DP) apresentou um padrão semelhante no período pós operatório imediato $(1309,5)$, de $3(1254,25)$ e 6 meses $(1219)$, porem mostrou aumento relevante aos 36 meses com valor médio de 1716,75 (Figura 7). 
Research, Society and Development, v. 10, n. 2, e31810212558, 2021

(CC BY 4.0) | ISSN 2525-3409 | DOI: http://dx.doi.org/10.33448/rsd-v10i2.12558

Figura 7 - Gráfico demonstrando as médias da densidade óssea para os períodos do pós operatório imediato, 3 , 6 e 36 meses de acompanhamento tomográfico na região vestibular (DV) e palatina (DP).

\section{Média da densidade óssea}

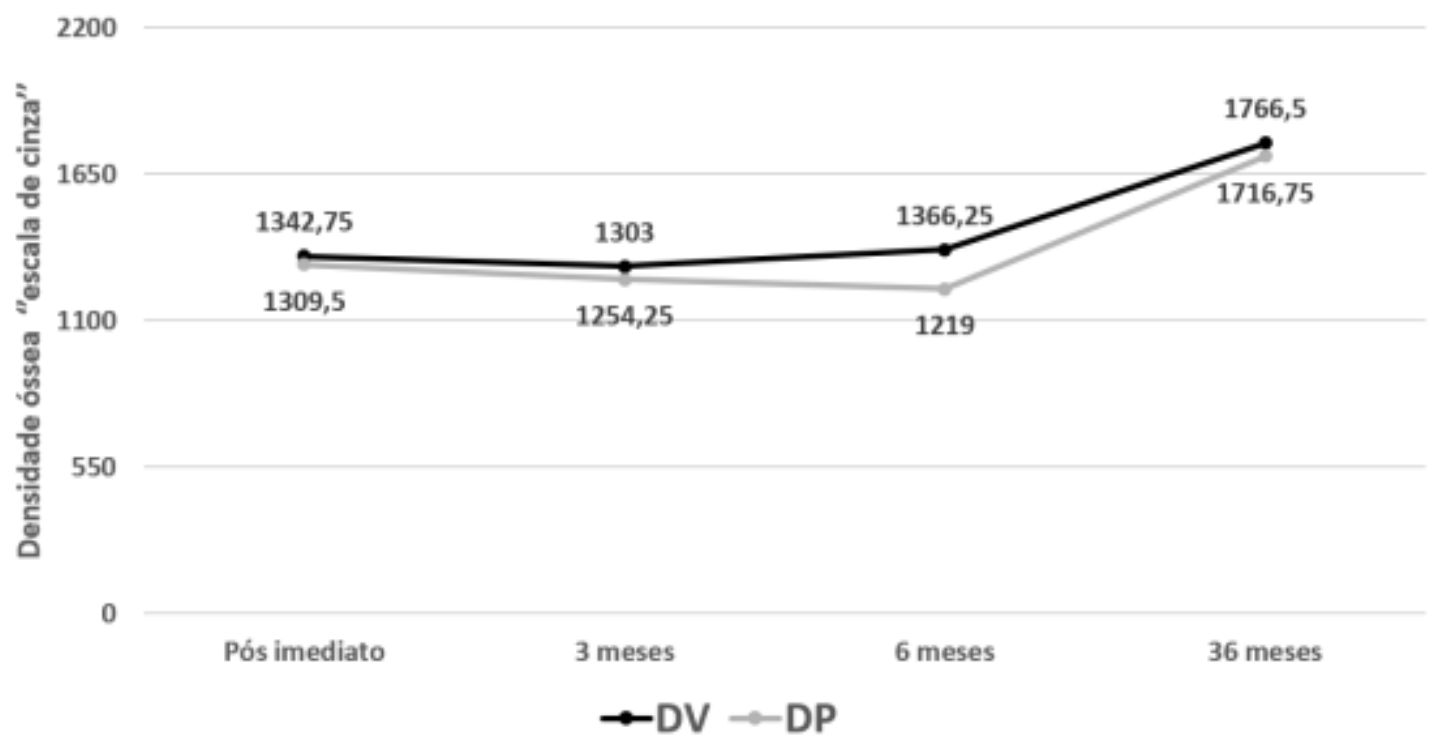

Fonte: Autores.

A média dos valores referentes a densidade óssea na porção vestibular e palatina dos dentes 15, 16, 26 e 27 nos diferentes tempos avaliados podem ser avaliados nos gráficos abaixo (Figura 8) 
Figura 8 - Gráficos demonstrando as médias de densidade óssea média para cada dente $(15,15,26$ e 27) individualmente, na região vestibular (DV) e palatina (DP) para cada período analisado (pós imediato, 3, 6 e 36 meses) de acordo com a escala de tons de cinza.
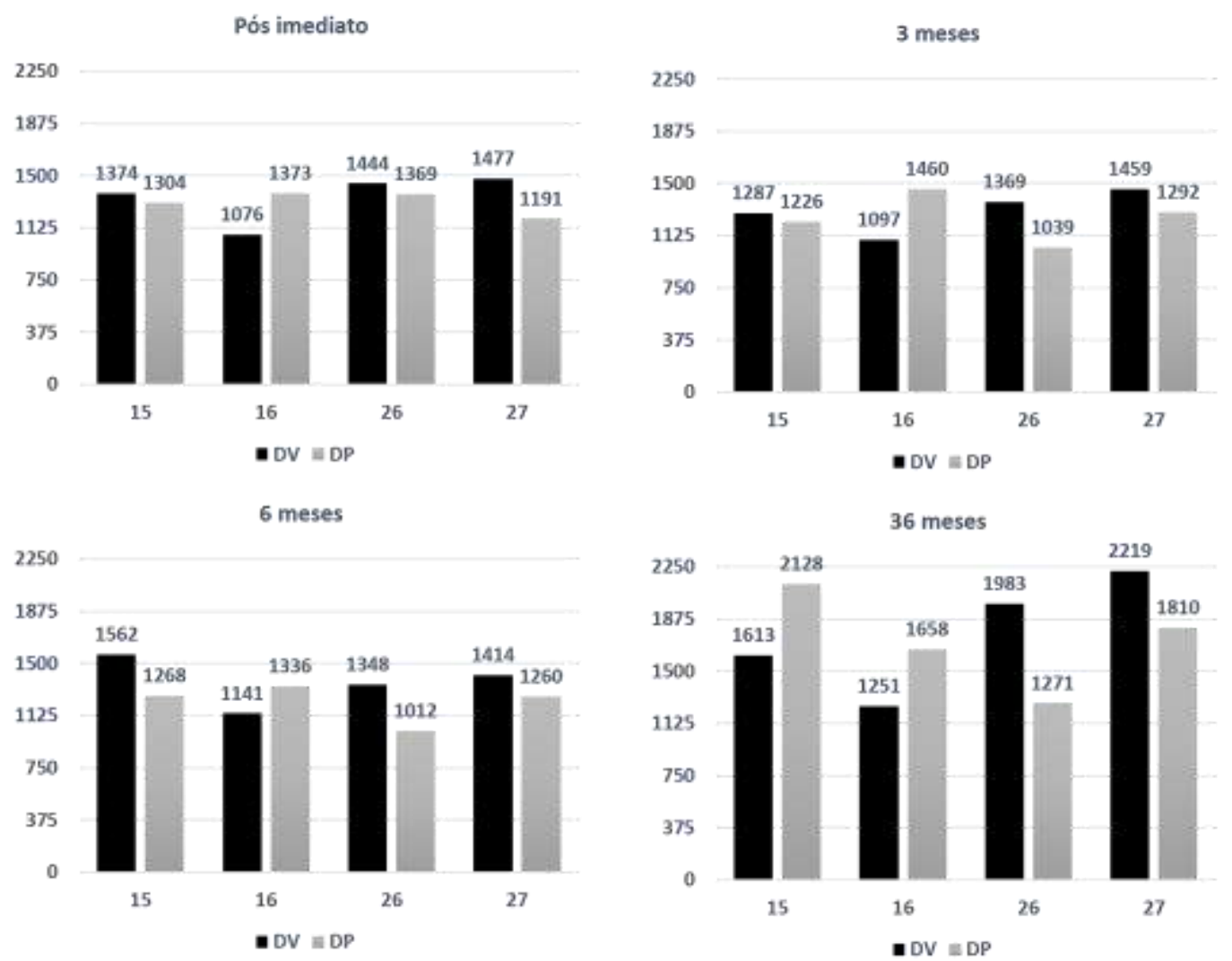

\subsection{Análise Histológica}

Fonte: Autores.

Em uma visão panorâmica da biópsia, pôde-se observar osso trabecular semelhante ao encontrado normalmente em região posterior da maxila, compatível com padrão de osso tipo IV, presença de trabeculado ósseo e tecido conjuntivo. No aumento de 12,5X é possível confirmar a presença de tecido ósseo lamelar. E em 40X a citoarquitetura óssea neoformada no interior do seio maxilar é compatível de fato com osso maduro com poucas áreas de osso imaturo (Woven bone) (Figura 9A, B e C). 
Figura 9 - (A) Análise histológica da biópsia em uma magnificação de 5x, (B) 12,5x demonstrando a presença de osso lamelar e, (C) 40x demonstrando a presença de osso neoformado com citoarquitetura compatível com osso maduro. Observar osteócitos viáveis na imagem $\mathrm{C}$, caracterizando tecido ósseo em atividade celular.

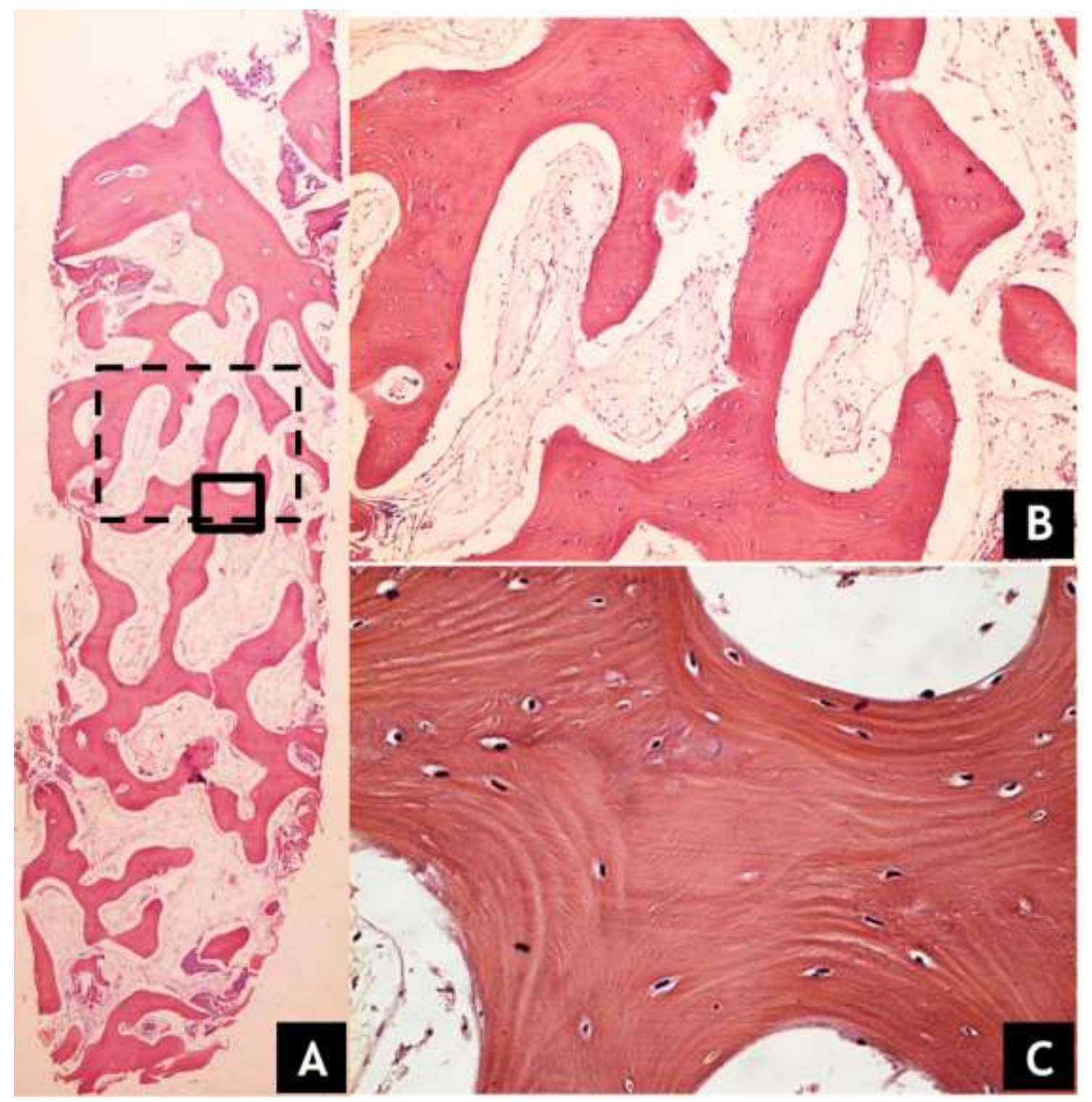

Fonte: Secção histológica da biópsia.

O resultado qualitativo detectado pela análise histológica foi avaliado por meio de uma análise histométrica do processo de reparo ósseo no seio maxilar, em lamina de aumento de 12.5X. Foi avaliada a porcentagem de osso formado e de tecido conjuntivo presente no período de 9 meses após a cirurgia de levantamento de seio sem utilização de biomaterial, o qual compreendia em $52 \%$ de tecido ósseo e $48 \%$ de tecido conjuntivo.

\section{Discussão}

Atualmente, o potencial de regeneração óssea do coágulo sanguíneo em cirurgias de elevação da membrana sinusal e instalação de implantes é cada vez mais corroborado pela literatura (Pinchasov et al., 2014 ; Moon et al., 2011 ; Lundgren et al., 2008; Riben et al., 2012). O presente caso mostrou que a técnica funcionou bem com o uso da parede óssea vestibular mantida na membrana durante a elevação do seio maxilar auxilia na manutenção do espaço intrassinusal para preenchimento 
pelo coágulo, evitando o colapso da membrana do seio maxilar ao implante, auxiliando assim na formação óssea e na estabilidade do implante em longo prazo. Quando levado em consideração, o ganho ósseo em altura avaliado aos 36 meses foi satisfatório para estabilidade e manutenção dos implantes. Um fator importante para o sucesso desta técnica, é o comportamento da membrana do seio maxilar, que junto com o periósteo pode produzir células osteoprogenitoras e os fatores humorais necessários para a regeneração óssea como osteocalcina, osteonectina, osteopontina e BMP2 quando há um coágulo estável envolvido (Bassi et al., 2015).

Alguns estudos mostram que não é necessária a utilização de membranas como barreira na janela da parede anterior do seio maxilar, apresentando resultados topográficos e histológicos satisfatórios.6 No entanto, outros estudos têm demonstrado que as aplicações dessas membranas apresentam vantagens. Entre eles, a redução da invaginação de partes moles, o aumento da formação óssea vital e o aumento da sobrevida dos implantes (Srouji et al., 2009). Nesse contexto, foi utilizada no presente caso uma membrana inabsorvível que se mostrou eficiente.

Em um estudo com cirurgia de levantamento de seio maxilar e instalação de implantes imediatos sem o uso de biomaterial, pode ser realizada com alto índice de sucesso, reduzindo a morbidade cirúrgica dos enxertos autógenos e algumas das limitações de outros enxertos osteocondutores. Também mostrou que há uma tendência de aumento da densidade óssea peri-implantar após a aplicação da carga funcional, com casos de sucesso observados em um acompanhamento até 51 meses depois (Pinchasov et al., 2014). Assim, esses dados encorajam ainda mais esse tipo de procedimento, assim como o caso presente, onde a indicação correta e bem executada é fator determinante para o sucesso do tratamento.

A função mastigatória por meio de estímulos fisiológicos promove um maior nível de maturação óssea peri-implantar (Tawil et al., 2001). No presente caso, é possível notar um aumento na qualidade do tecido ósseo, através do aumento do valor da densidade avaliada tomograficamente no período. de 36 meses de pós-operatório, período em que ocorreu carga mastigatória. Este resultado está de acordo com aqueles descritos por outros estudos (Pinchasov et al., 2014 ; Riben et al., 2012 ; Wallace et al., 2005).

Ganhos de volume e densidades ósseas são padrões extremamente importantes para avaliação pós-operatória nesses casos, mas fornecem apenas dados quantitativos (Nkenke et al., 2003). Para uma avaliação completa, os padrões qualitativos também devem ser avaliados por meio de análise histológica. Os resultados histológicos deste estudo indicam que no período de 9 meses (reabertura dos implantes), o osso formado corresponde a 52\% do espaço avaliado, apresentando uma característica de osso maduro com algumas regiões imaturas, comprovando que além de ganhos em volume e densidade, o osso formado tem, de fato, as características desejadas para maior estabilidade e dissipação das forças peri-implantar (Tavares et al., 2007).

\section{Conclusão}

Através dos resultados deste caso, após acompanhamento de 36 meses, pode-se concluir que a técnica de elevação do seio maxilar com colocação imediata do implante, sem o uso de biomateriais quando bem indicada, pode ser realizada com sucesso obtendo ganho de volume ósseo periimplantar com qualidade.

No entando, é necessário que se desenvolvam pesquisas clínicas bem delineadas e randozimadas a fim de obter respostas mais conclusivas em relação á tecninca apresentada nesse caso clínico, o potencial osteopromotor do coágulo e seu comportamento biológico durante o processo de reparo devem ser explorados.. Modificações como essa podem proporcionar ao paciente novas perspectivas em relação ao seu tratamento odontológico.

\section{Referências}

Thor, A., Sennerby, L., Hirsch, J. M., \& Rasmusson, L. (2007). Bone formation at the maxillary sinus floor following simultaneous elevation of the mucosal lining and implant installation without graft material: an evaluation of 20 patients treated with 44 Astra Tech implants. Journal of oral and maxillofacial surgery: official journal of the American Association of Oral and Maxillofacial Surgeons, 65(7, 1), 64-72. https://doi.org/10.1016/j.joms.2006.10.047 
Stern, A., \& Green, J. (2012). Sinus lift procedures: an overview of current techniques. Dental clinics of North America,56(1), 219-x. https://doi.org/10.1016/j.cden.2011.09.003

Lin, I. C., Gonzalez, A. M., Chang, H. J., Kao, S. Y., \& Chen, T. W. (2011). A 5-year follow-up of 80 implants in 44 patients placed immediately after the lateral trap-door window procedure to accomplish maxillary sinus elevation without bone grafting. The International journal of oral \& maxillofacial implants, 26(5), 1079-1086.

Pinchasov, G., \& Juodzbalys, G. (2014). Graft-free sinus augmentation procedure: a literature review. Journal of oral \& maxillofacial research, 5(1), e1. https://doi.org/10.5037/jomr.2014.5101

Moon, J. W., Sohn, D. S., Heo, J. U., Shin, H. I., \& Jung, J. K. (2011). New bone formation in the maxillary sinus using peripheral venous blood alone. Journal of oral and maxillofacial surgery: official journal of the American Association of Oral and Maxillofacial Surgeons, 69(9), 2357-2367. https://doi.org/10.1016/j.joms.2011.02.092

Sohn, D. S., Lee, J. S., Ahn, M. R., \& Shin, H. I. (2008). New bone formation in the maxillary sinus without bone grafts. Implant dentistry, 17(3), 321-331. https://doi.org/10.1097/ID.0b013e318182f01b

Bassi, A. P., Pioto, R., Faverani, L. P., Canestraro, D., \& Fontão, F. G. (2015). Maxillary sinus lift without grafting, and simultaneous implant placement: a prospective clinical study with a 51-month follow-up. International journal of oral and maxillofacial surgery,44(7), 902-907. https://doi.org/10.1016/j.ijom.2015.03.016

Falah, M., Sohn, D. S., \& Srouji, S. (2016). Graftless sinus augmentation with simultaneous dental implant placement: clinical results and biological perspectives. International journal of oral and maxillofacial surgery, 45(9), 1147-1153. https://doi.org/10.1016/j.ijom.2016.05.006

Lundgren, S., Cricchio, G., Palma, V. C., Salata, L. A., \& Sennerby, L. (2008). Sinus membrane elevation and simultaneous insertion of dental implants: a new surgical technique in maxillary sinus floor augmentation. Periodontology 2000, 47, 193-205. https://doi.org/10.1111/j.1600-0757.2008.00264.x

Pereira, A. S., Shitsuka, D. M., Parreira, F. J., \& Shitsuka, R. (2018). Metodologia da Pesquisa Científica (1a ed. E-book). Santa Maria: UAB/NTE/UFSM

Riben, C., \& Thor, A. (2012). The Maxillary Sinus Membrane Elevation Procedure: Augmentation of Bone around Dental Implants without Grafts-A Review of a Surgical Technique. International journal of dentistry, 2012, 105483. https://doi.org/10.1155/2012/105483

Bassi, A. P., Pioto, R., Faverani, L. P., Canestraro, D., \& Fontão, F. G. (2015). Dental implant placement after maxillary sinus lift without a graft: a feasible option. International journal of oral and maxillofacial surgery, 44(12), 1583-1584. https://doi.org/10.1016/j.ijom.2015.08.991

Srouji, S., Kizhner, T., Ben David, D., Riminucci, M., Bianco, P., \& Livne, E. (2009). The Schneiderian membrane contains osteoprogenitor cells: in vivo and in vitro study. Calcified tissue international, 84(2), 138-145. https://doi.org/10.1007/s00223-008-9202-x

Tawil, G., \& Mawla, M. (2001). Sinus floor elevation using a bovine bone mineral (Bio-Oss) with or without the concomitant use of a bilayered collagen barrier (Bio-Gide): a clinical report of immediate and delayed implant placement. The International journal of oral \& maxillofacial implants, 16(5), 713-721.

Wallace, S. S., Froum, S. J., Cho, S. C., Elian, N., Monteiro, D., Kim, B. S., \& Tarnow, D. P. (2005). Sinus augmentation utilizing anorganic bovine bone (Bio-Oss) with absorbable and nonabsorbable membranes placed over the lateral window: histomorphometric and clinical analyses. The International journal of periodontics \& restorative dentistry, 25(6), 551-559.

Nkenke, E., Lehner, B., Weinzierl, K., Thams, U., Neugebauer, J., Steveling, H., Radespiel-Tröger, M., \& Neukam, F. W. (2003). Bone contact, growth, and density around immediately loaded implants in the mandible of mini pigs. Clinical oral implants research, 14(3), 312-321. https://doi.org/10.1034/j.16000501.2003.120906.x

Tavares, M. G., de Oliveira, P. T., Nanci, A., Hawthorne, A. C., Rosa, A. L., \& Xavier, S. P. (2007). Treatment of a commercial, machined surface titanium implant with $\mathrm{H} 2 \mathrm{SO} 4 / \mathrm{H} 2 \mathrm{O} 2$ enhances contact osteogenesis. Clinical oral implants research, 18(4), 452-458. https://doi.org/10.1111/j.1600-0501.2007.01344.x 